\title{
Pleomorphic liposarcoma of the foot: a case report
}

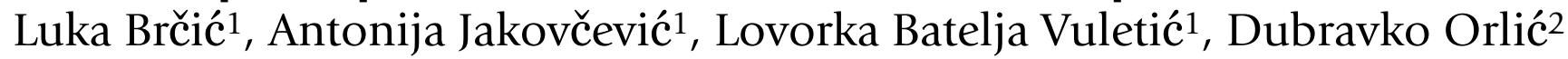 and Sven Seiwerth*1}

\author{
Address: ${ }^{1}$ Institute of Pathology, Medical School, University of Zagreb, Šalata 10, Zagreb, Croatia and ${ }^{2}$ Department of Orthopedics, Medical \\ School, University of Zagreb, Šalata 6, Zagreb, Croatia \\ Email: Luka Brčić - lbrcic@mef.hr; Antonija Jakovčević - antonia.jakovcevic@yahoo.com; Lovorka Batelja Vuletić - lbatelja@mef.hr; \\ Dubravko Orlić - orlic@mef.hr; Sven Seiwerth* - seiwerth@mef.hr \\ * Corresponding author
}

Published: 16 April 2008

Diagnostic Pathology 2008, 3:15 doi:10.1186/1746-1596-3-15

This article is available from: http://www.diagnosticpathology.org/content/3/1/15

(C) 2008 Brčić et al; licensee BioMed Central Ltd.

This is an Open Access article distributed under the terms of the Creative Commons Attribution License (http://creativecommons.org/licenses/by/2.0), which permits unrestricted use, distribution, and reproduction in any medium, provided the original work is properly cited.
Received: 14 December 2007

Accepted: 16 April 2008

\begin{abstract}
Background: Liposarcomas are among the most common sarcomas of adult life. Pleomorphic liposarcoma, characterized by pleomorphic lipoblasts, is the rarest subtype. To our knowledge only three cases of pleomorphic liposarcoma of the foot or ankle have been reported so far.

Case presentation: A $7 \mathrm{I}$-year-old female presented with a large growing mass on the dorsum of her right foot. Computed tomography showed invasive tumorous mass. Excision biopsy revealed the mass to be a pleomorphic liposarcoma, and below the knee amputation was performed.

Conclusion: Although the incidence of pleomorphic liposarcoma in the foot is very low, it is essential to perform thorough histological analysis of all soft tissue masses, regardless of their benign appearance, because only prompt radical surgery can result in a good prognosis for the patient.
\end{abstract}

\section{Background}

Liposarcomas are malignant tumors and among the most common soft tissue sarcomas of adult life [1]. They can be devided according to clinicopathologic and cytogenetic characteristics into three distinct subtypes: well-differentiated, myxoid/round cell and pleomorphic liposarcoma $[1,2]$. Pleomorphic liposarcomas are the rarest, and are characterized by the presence of pleomorphic lipoblasts. According to recent studies [3-5] pleomorphic liposarcomas occur most often in lower and upper limbs, and only three have been found in foot and ankle, one of them occurring in a burn scar [6].

We present a case of a pleomorphic liposarcoma of the foot, stressing necessity of a proper histological analysis, followed by radical surgery leading supposedly to a better prognosis for the patient.

\section{Case presentation}

A 71-year-old female of normal weight presented with a large mass on the dorsum of her right foot which has been gradually increasing in size over 4 months prior to admission to the hospital. Two years before she had a soft tissue injury at the same location, but without any complication and sequels. Otherwise she was without serious illness. Her family history revealed no lipomatous disorders. On physical examination a firm, palpable tumor mass, 6-7 $\mathrm{cm}$ in diameter, poorly-defined from surrounding tissue and attached to underlying structures and skin, was detected. The mass was painless, unless examined by deep 


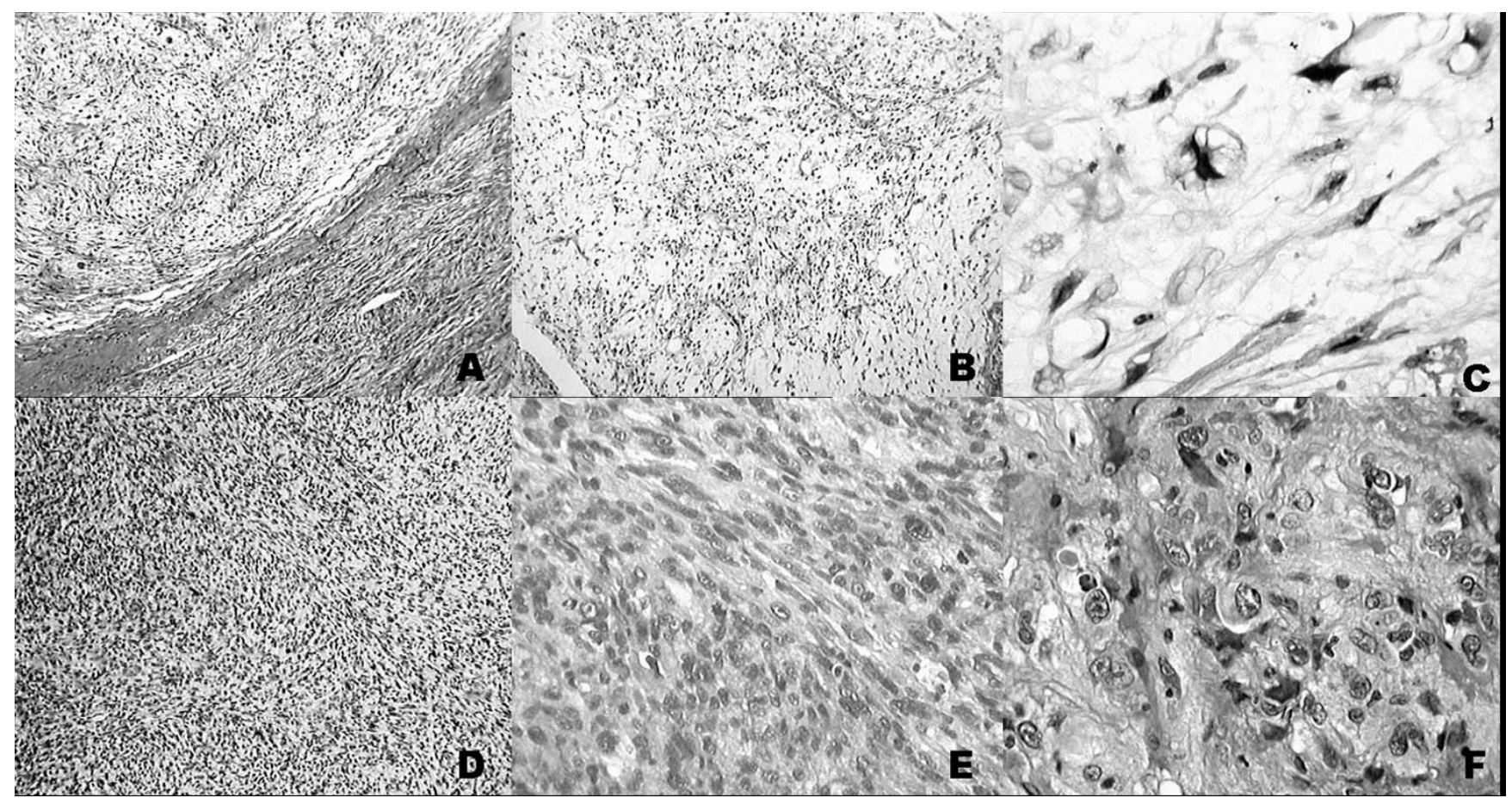

\section{Figure I}

Histological presentation. Histological presentation of lipogenic and nonlipogenic areas (A), with pleomorphic lipoblasts (B, C) in lipogenic areas. In nonlipogenic areas pleomorphic spindle cells were interspersed with dense collagen (D, E), while some showed rhabdoid or epitheloid features (F). (hemalaun-eosyn staining; A, B, D-objective $\times 2$; C, F-objective $\times 25$; E-objective $\times 6.3)$

palpation. Skin above it was of normal color and structure. Laboratory findings, including blood count, were completely normal. On plain x-rays only an ill defined mass on the dorsum of the foot, with no clear correlation to the bone, was observed. Computed tomography revealed invasive tumorous mass. Scintigraphy with Tc99 was positive. Magnetic resonance imaging showed expansive infiltrative process of the dorsum of the foot with penetration between metatarsal bones to the plantar side, and partial destruction of the fourth metatarsal bone. Histologically, in biopsy sample, areas with lipogenic characteristics were surrounded by nonlipogenic areas (Figure 1A). In lipogenic areas lipoblasts of different size and shape with variably expressed pleomorphism and number of nuclei were found (Figure 1B,C). The number of lipoblasts also varied considerably from field to field as was the intensity of mixoid change so that some areas had a myxofibrosarcoma-like appearance, a pattern dominating the first biopsy (Figure 1). In nonlipogenic areas sheets of pleomorphic spindle cells with multinucleated giant cells (complying to the pattern of so called malignant fibrous histiocytoma, MFH) were interspersed with more pleomorphic parts or dense collagen (Figure 1D,E). Occasionally some cells showed rhabdoid or epitheloid features (Figure 1F). No significant necrosis was present. A panel of antibodies was studied immunohistochemically: vimentin, S-100, desmin, CD34, CD68, cytokeratin, epithelial membrane antigen (EMA), myoglobin, myogenin and smooth muscle actin (SMA) (all antibodies from DAKO; Copenhagen, Denmark). In tumor cells S-100 was occasionally positive with better expression in lipogenic than in non-lipogenic areas. Positivity for CD68 and myogenin were observed rarely. CD 34 and SMA were positive only in vessel walls, and negative in tumor, while other antibodies yielded no specific staining. Proliferation rate measured with Ki-67 was $40 \%$ measured in hot spot areas.

After histological diagnosis below the knee amputation was indicated. No further therapy was indicated, and patient is still alive, 6.5 years after the diagnosis was made.

\section{Discussion}

Pleomorphic liposarcoma is a rare neoplasm, and until know there have been only 3 reported cases of pleomorphic liposarcoma in the foot and ankle. It is known that this neoplasm is usually aggressive, occurring in adulthood, and usually in the limbs. Pleomorphic liposarcoma can occur in mediastinum, liver, orbit, paratesticular region, and also as a purely dermal tumor [3,4,7-11] and are presented as single case studies or in review articles. It 
usually presents as a painless, deep-seated tumorous mass [3]. It can easily be misdiagnosed, because of the great variety of histological presentations. Histological hallmark of pleomorphic liposarcoma are pleomorphic lipoblast, which can form less than $10 \%$ of the tumor. Immunohistochemistry has a limited value in diagnostic procedures. According to Gebhard et al. S-100 protein immunoreactivity can be observed in up to $48 \%$ of lipogenic areas, while SMA was positive in $49 \%$ of nonlipogenic areas of pleomorphic liposarcoma [3]. They differentiate four morphological subtypes of pleomorphic liposarcoma, based on the appearance of nonlipogenic parts of the tumor: malignant fibrous histiocytoma-like, epithelioid, round cell and spindle cell liposarcoma-like. This classification is in contrast with the view of Enzinger and Weis recognizing only 2 subtypes (MFH-like and with round and pleomorphic cells) [2]. Some dedifferentiated and pleomorphic liposarcomas have been reported to be associated with leukocytosis. This feature, usually expressed in MFH, led to the concept of possible common lineage for $\mathrm{MFH}$, dedifferentiated and pleomorphic liposarcoma [12]. Differential diagnosis includes dedifferentiated liposarcoma, myxofibrosarcoma, leiomyosarcoma, rhabdomyosarcoma, carcinoma, and melanoma, which may be difficult to distinguish especially in small biopsies. This is especially true for dedifferentiated liposarcoma where quality of sampling represents the key parameter in avoiding underdiagnosis. Only adequate sampling will identify both well/and poorly differentiated areas of a given tumor. The distinction from nonlipogenic tumors is based on demonstration of multivacuolated lipoblasts and occasional positivity for S-100 protein in the spindle or poorly differentiated areas. The most complicated task is the differential diagnosis of tumors with highly pleomorphic (MFH-like) features. The differential diagnosis in the groups with round or pleomorphic cells, including epitheloid appearance, largely depends on specific immunohistochemistry for the given tumors. In distinction from poorly differentiated epithelial neoplasms the positivity of occasional cells for epithelial markers should be kept in mind [13]. In all cases inadequate sampling represents one of the basic problems.

Molecular studies so far yielded little useful results: in one third of the patients MDM2 amplification was detected, and TP53 alterations were present in four out of nine patients (all without MDM2 amplification) [14].

We presented a case of a 71-year old female, with tumorous mass on the dorsum of her right foot, which, according to pathohistological analysis, turned out to be a pleomorphic liposarcoma, showing areas of different histology. Our case demonstrates the importance of pathohistological analysis of all soft tissue tumorous masses in the foot/ankle region, which may look like common benign soft tissue lesions, but if not recognized can become life-threatening.

\section{Conclusion}

It is important to bear in mind that the differential diagnosis of pleomorphic lyposarcoma is fairly broad and that thorough sampling and searching for lipoblasts may be rewarding in tumors firstly presenting histologically as one of the mimics (e.g. MFH, myxofibrosarcoma or even metastatic carcinoma or melanoma).

\section{Competing interests}

The authors declare that they have no competing interests.

\section{Authors' contributions}

LB is primarily responsible for drafting, literature search and submission of the manuscript. AJ and LBV vere involved in literature search and preparing the material, DO suplyed relevant clinical information about the patient and was involved in manuscript revision. SS outlined the general concept of the manuscript, has been involved in drafting and revising it critically. All authors have read and approved the final manuscript.

\section{References}

I. Fletcher CDM: Soft tissue tumors. In Diagnostic Histopathology of Tumors 2nd edition. Edited by: Fletcher CDM. London: Churchill Livingstone; 2000: 1473-1540.

2. Weiss SW, Goldblum JR: Liposarcoma. In Enzinger and Weiss's Soft Tissue Tumors 4th edition. Edited by: Weiss SW, Goldblum JR. St Louis, MO: Mosby; 200I:64I-693.

3. Gebhard S, Coindre JM, Michels JJ, Terrier P, Bertrand G, Trassard M, Taylor S, Château MC, Marquès B, Picot V, Guillou L: Pleomorphic liposarcoma. Clinicopathologic and immunohistochemical study of 63 cases. A study of the French Sarcoma Group. Am J Surg Pathol 2002, 26:601-616.

4. Downes KA, Goldblum JR, Montgomery EA, Fisher C: Pleomorphic liposarcoma: a clinicopathological analysis of 19 cases. Mod Pathol 200I, 14:179-184.

5. Hornick JL, Bosenberg MW, Mentzel T, McMenamin ME, Oliveira AM, Fletcher CD: Pleomorphic liposarcoma. Am J Surg Pathol 2004, 28:1257-I267.

6. Nishimoto S, Matsushita T, Matsumolo K, Adachi S: A rare case of burn scar malignancy. Burns 1996, 22:497-499.

7. Cai YC, Mc Menamin ME, Rose G, Sandy CJ, Cree IA, Fletcher CD: Primary liposarcoma of the orbit: A clinicopathological study of seven cases. Ann Diagn Pathol 200 I, 5:255-266.

8. Dei Tos AP, Mentzel T, Fletcher CD: Primary liposarcoma of the skin: a rare neoplasm with unusual high grade features. $\mathrm{Am} J$ Dermatopathol 1998, 20:332-338.

9. Klimstra DS, Moran CA, Perino G, Koss MN, Rosai J: Liposarcoma of the anterior mediastinum and thymus. A clinicopathologic study of 28 cases. Am J Surg Pathol 1995, 19:782-79|.

10. Miettinen M, Enzinger FM: Epithelioid variant of pleomorphic liposarcoma: a study of 12 cases of a distinctive variant of high-grade liposarcoma. Mod Pathol 1999, I 2:722-728.

II. Oliveira AM, Nascimento AG: Pleomorphic liposarcoma. Semin Diagn Pathol 200I, 18:274-285.

12. Sakamoto A, Matono H, Yoshida T, Tanaka K, Matsuda S, Oda Y Iwamoto $Y$ : Dedifferentiated liposarcoma with leukocytosis. A case report of G-CSF-producing soft tissue tumors, possible association with undifferentiated liposarcoma lineage. World J Surg Oncol 2007, 5:131.

13. Mentzel T, Pedeutour F: Pleomorphic liposarcoma. In Pathology and Genetics of Tumours of Soft Tissue and Bone Edited by: Fletcher CDM, Unni KK, Mertens F. Lyon: IARC Press; 2002:64I-693. 
14. Schneider-Stock R, Walter H, Radig K, Rys J, Bosse A, Kuhnen C, Hoang-Vu C, Roessner A: MDM2 amplification and loss of heterozygosity at Rb and p53 genes: no simultaneous alterations in the oncogenesis of liposarcomas. J Cancer Res Clin Oncol 1998, 124:532-540.

Publish with Bio Med Central and every scientist can read your work free of charge

"BioMed Central will be the most significant development for disseminating the results of biomedical research in our lifetime. " Sir Paul Nurse, Cancer Research UK

Your research papers will be:

- available free of charge to the entire biomedical community

- peer reviewed and published immediately upon acceptance

- cited in PubMed and archived on PubMed Central

- yours - you keep the copyright

Submit your manuscript here:

http://www.biomedcentral.com/info/publishing_adv.asp 